Jarosław CISZKOWSKI, Paweł NISZCZOTA, Przemysław KROGULEC Air Force Institute of Technology (Instytut Techniczny Wojsk Lotniczych)

\title{
PROTOTYPE OF A DEVICE USED FOR DYNAMIC BALANCING POWER UNITS OF UNMANNED PLATFORMS
}

\section{Prototyp stanowiska do dynamicznego wyważania zespołów napędowych platform bezzalogowych}

\begin{abstract}
The paper presents a prototype of a device used for dynamic balancing of motors and power units utilized in the construction of unmanned electric aerial vehicles. The concept of research was described and a measuring system depiction was included. A threedimensional model of a device functional prototype with its description was demonstrated. Additionally, research results of the system in the form of graphs were included.
\end{abstract}

Keywords: dynamic balancing device, brushless motor, power unit

Streszczenie: $W$ pracy przedstawiono prototyp urzadzenia stużacego do wyważania dynamicznego silników i zespotów napędowych wykorzystywanych w budowie bezzałogowych statków powietrznych z napędem elektrycznym. Opisano koncepcję badań, a także zawarto opis systemu pomiarowego. Zademonstrowano model bryłowy urządzenia, prototyp funkcjonalny wraz z opisem. Dodatkowo zamieszczono wyniki badań systemu w postaci wykresów.

Słowa kluczowe: stanowisko do wyważania dynamicznego, silnik bezszczotkowy, zespół napędowy 


\section{Introduction}

In the field of light unmanned aircraft, the most common propulsion type is a unit consisting of a brushless electric motor, regulator and propeller. This system has many advantages, such as high motor efficiency, long life, ease of use, but like any rotating device, it requires careful balancing in order to avoid vibrations.

The vibrations generated by the power unit in the construction of unmanned aircraft have a number of adverse effects, among others, such as:

- faster wear of the rotors' bearings,

- increase of the noise level in the environment of rotating elements,

- disturbed operation of electronic flight stabilisation systems,

- fatigue cracking of mechanical elements,

Each of the above-mentioned factors may lead to complete damage to unmanned aircraft and threaten its immediate surroundings.

If there is symmetrical mass distribution to the axis of rotation of the rotating element, then centrifugal forces caused by these masses counterbalance each other. Such elements are treated as balanced. A device with balanced elements operates without vibrations and noise. In an object rotating with a known angular velocity, which has asymmetrical mass distribution, there is an unbalance condition characterised by the formation of an unbalanced centrifugal force. The occurrence of the unbalance condition is manifested by intensive vibrations of the rotor, bearings, etc. [2].

There are two balancing methods: static and dynamic [5].

Static balancing makes it possible to detect the mass centre position outside the axis of rotation, and then, to add or take the mass in a precisely defined place in order to equalise the centre of the system mass with the axis of rotation. The statically balanced body remains stationary and the mass centre coincides with the axis of rotation (there is no tendency for the element rotation under the influence of gravity). The static balancing does not allow to determine the asymmetry of the mass distribution along the axis of rotation.

Dynamic balancing allows to correct the position of the mass centre of the element along its axis of rotation. It is performed by analysing the moments of forces generated by the rotating element. In the dynamically balanced element, may exist unbalanced centrifugal forces [7].

The mass distribution correction in relation to the axis of rotation is carried out at balancing stations with two methods: removal machining consisting in removing the material excess or adding the balancing up mass.

Static methods are generally used for balancing propellers. In case of propellers (rotors) of power units with the power of not more than $500 \mathrm{~W}$, the basic element of the static balancing station is a steel shaft with embedded cones fixing the propeller in a specific position fig. 1. One of the cones is permanently attached to the shaft. The second one is adjustable in feed and locked in relation to the shaft by thread connection or a rubber ring. 


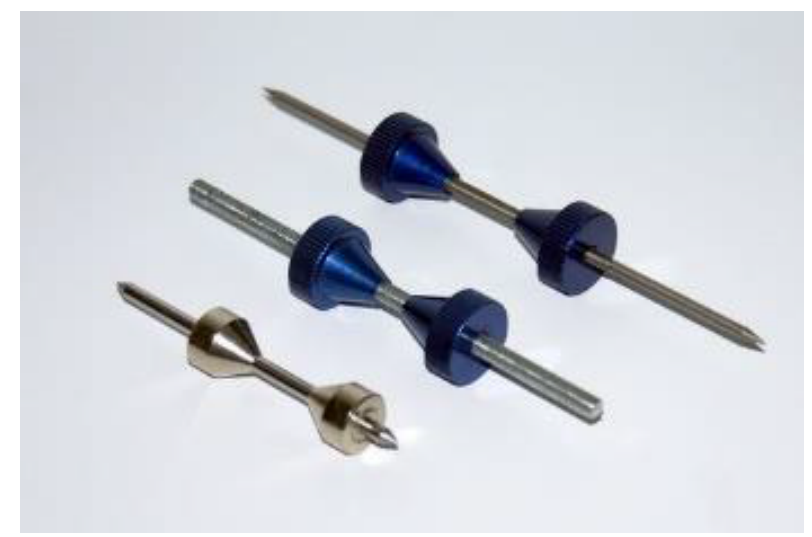

Fig. 1. Static balancing machines' shafts [source: www.modelmotor.pl/webpage/wywazaniesmigiel.html]

A popular solution used in balancing stations is the support of a steel shaft together with the propeller mounted on two accurately levelled supports. The composition of each support consists of a pair of rollers that allow for the shaft rotation. The described station is presented in fig. 2.

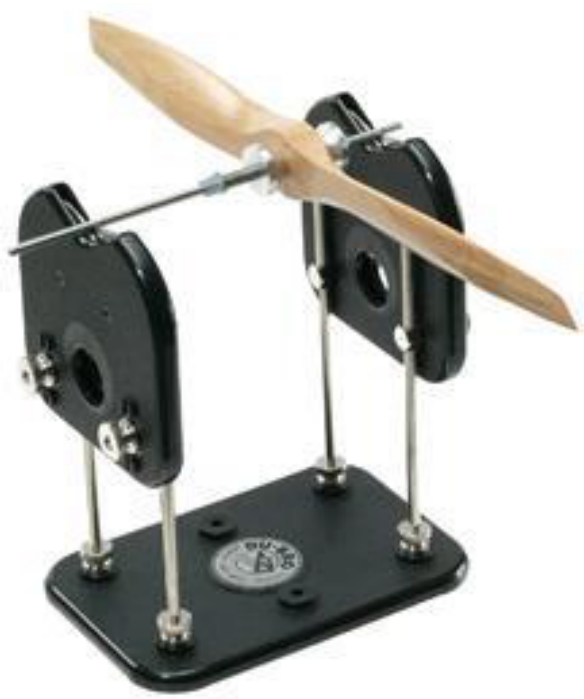

Fig. 2. The static balancing station mounted in bearings [source: www.dubro.com/products/tru-spinprop-balancer]

Another solution used in static balancing is the suspension of the shaft with the propeller in the magnetic field. In this case, instead of a pair of rollers, there are magnets in the supports fig. 3. The advantage of this solution is no mechanical friction. Tests at this station are limited to propellers of low mass and diameter. 


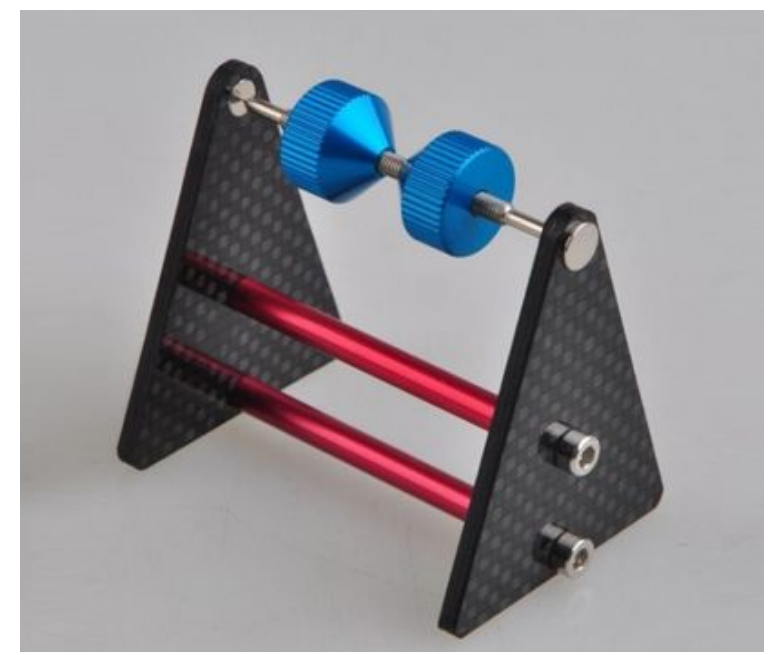

Fig. 3. Static balancing station with magnets [source: www.modelmotor.pl/webpage/wywazaniesmigiel.html]

In static balancing stations, a heavier side of the propeller falls down due to gravity. If the propeller does not rotate from any initial position, it can be assumed that the propeller is balanced. In the unbalanced propeller, the shaft always rotates after removing the support. The station role is to detect the tendency of rotation and its direction. Then, on the lighter side of the propeller, mass is added to the leading edge. Its size and location from the axis of rotation are unknown and they should be determined experimentally. The static balancing process is iterative. The static balancing is a correct, but time-consuming, method.

The dynamic balancing methods are used in the motors and entire power units (motor + propeller). The existing solutions use an acceleration sensor in the plane perpendicular to the axis of rotation and a motor shaft rotational speed sensor. The motor is screwed to the base included in a flexible pad made of vibration isolators. The station is equipped with an electronic control system and software that make it possible to operate the station as well as to record and analyse data. This type of the dynamic balancing station analyses the measurements in real time and calculates the angular position of the required correction mass in relation to the rotor. The above station does not allow to determine the balancing up mass value. Balancing is iterative, similar to the static balancing method. Figure 4 shows a balancing device made using 3D printing technology.

In industrial applications, sound and vibration signals are used to diagnose electric motors $[1,3]$. 


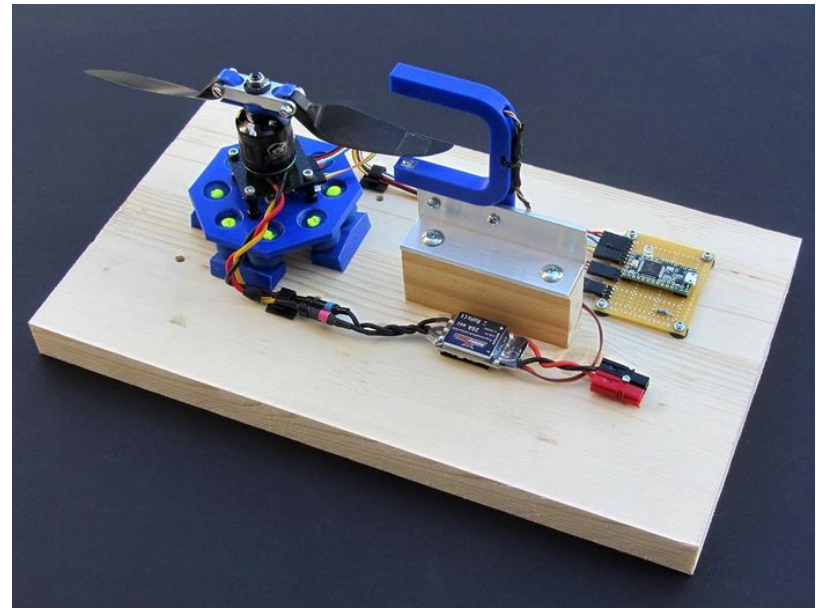

Fig. 4. Dynamic balancing station of the power unit [source: http://itsqv.com/QVM/ index.php? title=DIY_-_Dynamic_Motor_and_Prop_Balancer

\section{Taken issue}

The existing solutions of balancing devices, both static and dynamic, are mostly impractical. Their accuracy depends on the operator's skills and experience. Any of the devices gives precise balancing up mass values, and only some of them indicate the place of its addition. Accordingly, at the Air Force Institute of Technology, an attempt was made to improve the available constructional solutions and to implement a dynamic balancing station that allows to increase the measurement accuracy. The station makes it possible to test power units consisting of motor, hub and propeller as well as the motors themselves. It is assumed to perform calculation algorithms, electronic control systems and dedicated software.

\section{Research concept}

The unbalanced rotating element generates a non-zero resultant centrifugal force. In order to balance it, the mass distribution of rotating elements should be changed in such a way that the mass difference on the line parallel to the vector of the resultant centrifugal force and passing through its attachment point balances the unbalance centrifugal force. Therefore, for dynamic balancing, it is important to determine the amount of the mass correction and the arm on which it is set. For this purpose, it is proposed to build a test stand which allows to measure the acceleration in three axes and in two planes generated by unbalance of the rotating object. Figure 5 shows exemplary unbalanced a) and balanced b) 
arrangement. Accelerometers and the motor will be connected with the fixed housing with the use of elements susceptible to known characteristics. Based on the knowledge of accelerations and the station geometry, the turn and direction of force, which should be balanced in relation to the contractual angle of $0^{\circ}$, will be specified.

a)

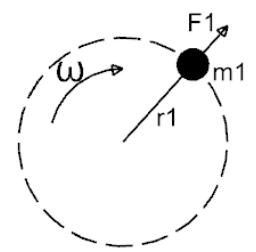

b)

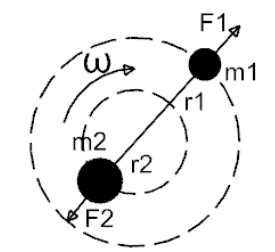

$\mathrm{r} 1=2^{\star} \mathrm{r} 2, \mathrm{~m} 1=0,5^{\star} \mathrm{m} 2, \mathrm{~F} 1=\mathrm{F} 2$

Fig. 5. Diagram of a rotating system a) unbalanced system, b) balanced system

\section{Station description}

The dynamic balancing station consists of a mechanical part, the tested power unit or the motor itself, as well as a measuring part using electronic sensors.

\subsection{Station construction}

The dynamic balancing station of power units was proposed in the composite construction. The basic element of the device is a stand, to which two accelerometers are attached, the measuring axes of which have common directions. Both sensors are located relative to each other at a distance of $120 \mathrm{~mm}$. In addition, the power unit is equipped with an incremental (growth) encoder that makes it possible to measure the angle and rotational speed. Another important element of the device is an external frame. It is made of two side walls permanently connected with a pair of upper and bottom bars. The stand is suspended on the frame with the use of eight susceptible elements (flexible pads). The selection of elements with appropriate elasticity and damping coefficients is important due to the resonance effect occurring in elastic systems. The frame is attached to a rigid and levelled base. The station construction is presented in fig. 6. For the proposed solution, the possibility of balancing up the power unit along the axis $\boldsymbol{z}$ (motor rotation axis), as well as detecting the nature of vibrations owing to two accelerometers are assumed.

The coordinate system was adopted in fig. 6 . The angle indicating the motor shaft position is calculated clockwise in the plane $\boldsymbol{x y}$ (in relation to the axis $\boldsymbol{z}$ ). The zero value was adopted on the positive semi-axis $\boldsymbol{x}$. 


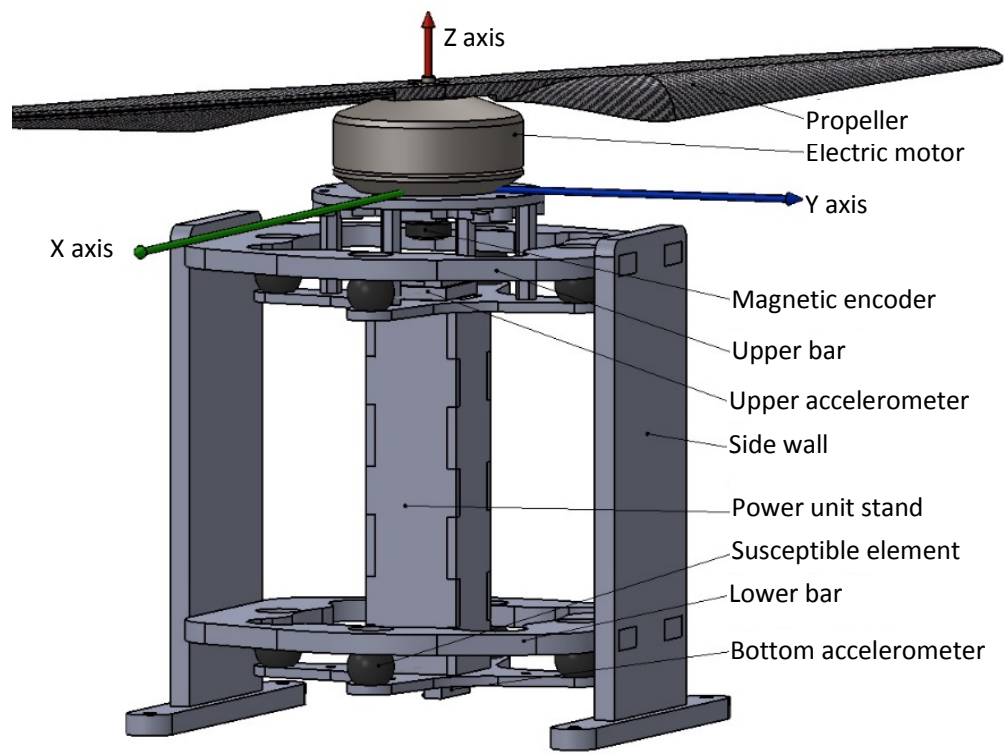

Fig. 6. Dynamic balancing station construction

\subsection{Measuring sensors}

In order to determine the linear accelerations, an MPU-6050 three-axis accelerometer using the $\mathrm{I} 2 \mathrm{C}$ communication bus was applied. The sensor has the ability to configure the measuring ranges to the following values: $\pm 2 \mathrm{~g}, \pm 4 \mathrm{~g}, \pm 8 \mathrm{~g}, \pm 16 \mathrm{~g}$. The measurement accuracy in the axes $\boldsymbol{x}$ and $\boldsymbol{y}$ is $\pm 50 \mathrm{mg}$ and in the axis $\boldsymbol{z} \pm 80 \mathrm{mg}$. The symbol of gravitational acceleration is "g" and will be used consistently in this sense, except when used as a unit of mass (gram) which will be mentioned in the text. Figure 7 shows the sensor construction with a description of outputs.
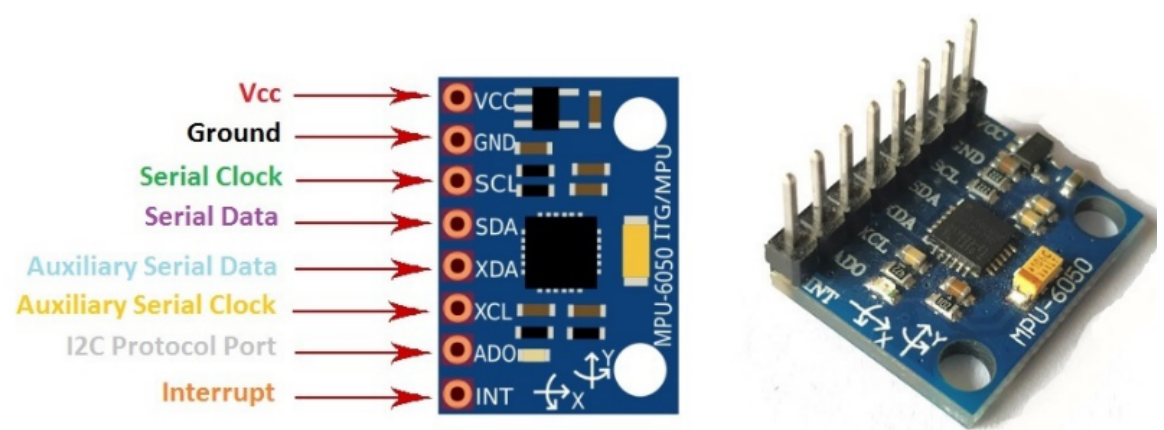

Fig. 7. MPU-6050 construction with a description of outputs [source: http://www.theengineeringprojects.com/2019/02/introduction-to-mpu6050.html] 
In order to measure the propeller's rotation angle and rotational speed, the CPR 48 incremental encoder of the Pololu company was applied (fig. 7). The principle of its operation is based on the Hall effect. The angle measurement is implemented every $7.5^{\circ}$.

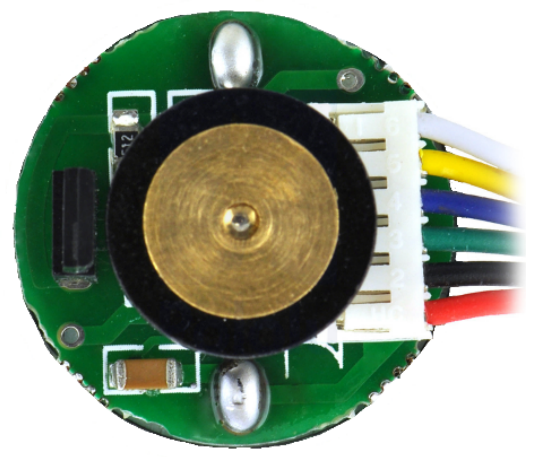

Fig. 8. CPR 48 encoder with the magnet mounted on the shaft [source: https://www.pololu.com]

The sensors are connected to the DISCOVERY F4 electronic system using the STM32F4 microcontroller. The processor performs the function of receiving data from the MPU6050 sensor and the Encoder. Then, the data is sent to a PC.

\subsection{Power unit}

The power unit most commonly used in the class of light unmanned aircraft is brushless motor and propeller systems rigidly connected and providing thrust. The motor stator is mounted to the unmanned aircraft platform, while the propeller is screwed to the rotor.

The studies used a brushless DC motor (Brushless Direct Current motor, BLDC for short) MN5208 of the T-Motor company. This motor is used in the Atrax M unmanned aircraft that was designed and manufactured at the Air Force Institute of Technology.

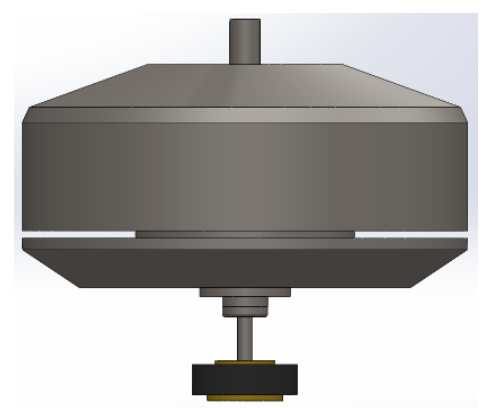

Fig. 9. T-Motor motor with an embedded magnet [source: http://en.tmotor.com/index.php?q= MN5208\&m=search\&c=index\&a=init\&typeid=55\&siteid=2] 
The propeller used for testing is also of the T-Motor company with the dimensions of $13 \times 4.4$ ". It is made of carbon composite, owing to which it is lightweight and durable, and at the same time, rigid, which in comparison with polymer propellers promotes the formation of larger vibrations. Figure 10 presents a fragment of the Atrax M unmanned aircraft arm with a power unit used in the tests.

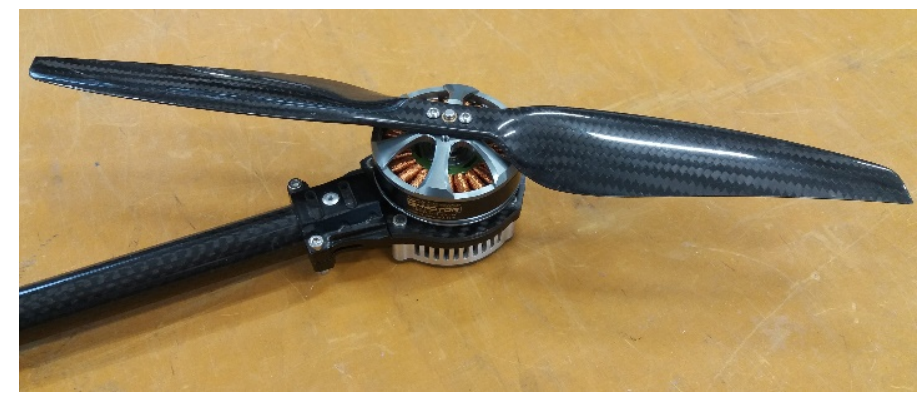

Fig. 10. Atrax $M$ unmanned aircraft arm with a power unit

\section{Research results}

The experimental research cycle was started with the activation of acceleration sensors with the motor off. The measuring range was adopted as $\pm 2 \mathrm{~g}$. The recorded overloads in the axes $\boldsymbol{x}, \boldsymbol{y}, \boldsymbol{z}$ for two sensors, a moment after turning the power supply on, were presented in fig. 11. Residual values of overloads in three axes $\boldsymbol{x}, \boldsymbol{y}, \boldsymbol{z}$ may indicate that the research platform is not levelled. Therefore, it was necessary to calibrate the sensors as a result of which the acceleration in the axes $\boldsymbol{x}$ and $\boldsymbol{y}$ were set at zero, while in the axis $\boldsymbol{z}$, the indicated acceleration was equal to gravitational acceleration.

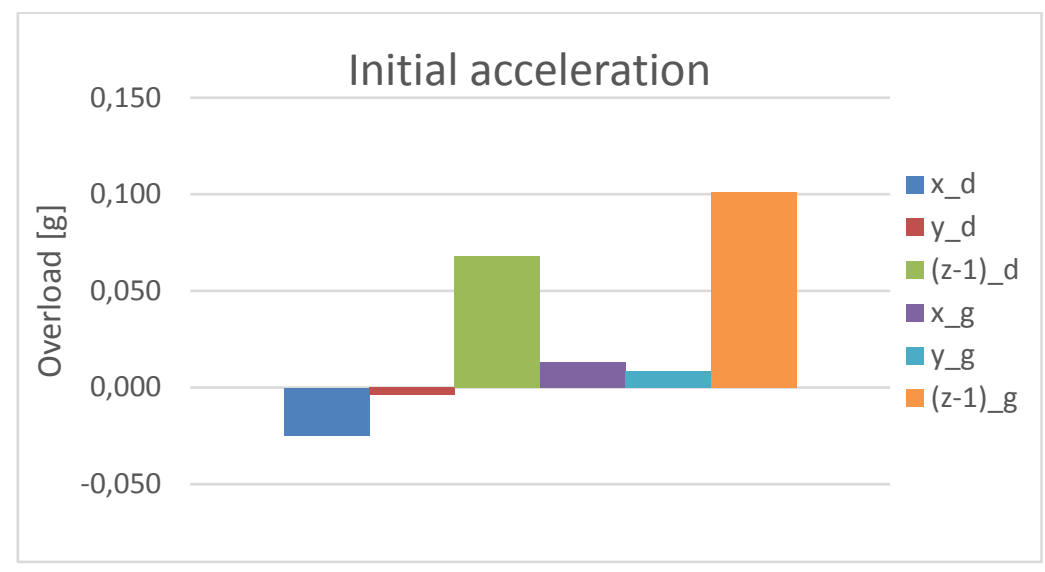

Fig. 11. Overload values recorded by accelerometers 
The test stand has elastic suspension characterised by elasticity and damping coefficients. For the station, assuming the immobilised power unit, the vibration induced by operation of a single step pulse is of damped free vibration nature.

The unbalanced motor rotating at a given angular velocity is a source of a vibration exciting force. The exciting force frequency is independent of the natural vibration frequency of the system that always vibrates with the exciting force frequency $[4,6]$. The knowledge of the exciting force and natural vibration frequencies is crucial due to the resonance effect. The resonance occurs when the exciting force frequency equals the natural vibration frequency, which means synchronisation of the exciting force and elastic force.

For the test stand, a natural vibration period was determined with the use of the theory of damped free vibrations. During the measurements, the motor was turned off (no exciting force from the unbalanced motor). The vibration waveforms were recorded in the axes $\mathbf{x}$ and $\boldsymbol{y}$. Figure 12 presents damped free vibration waveforms in the time function for the upper accelerometer. Resulting from the fact of the measuring range selection of the acceleration sensor equal to $\pm 2 \mathrm{~g}$, fig. 12 shows that there are no recorded measurement points. On the basis of the graph, a vibration period of $57.815 \mathrm{~ms}$ was calculated, which is equivalent to $17.29 \mathrm{~Hz}$ and corresponds to a rotational speed of $1037.8 \mathrm{rpm}$.

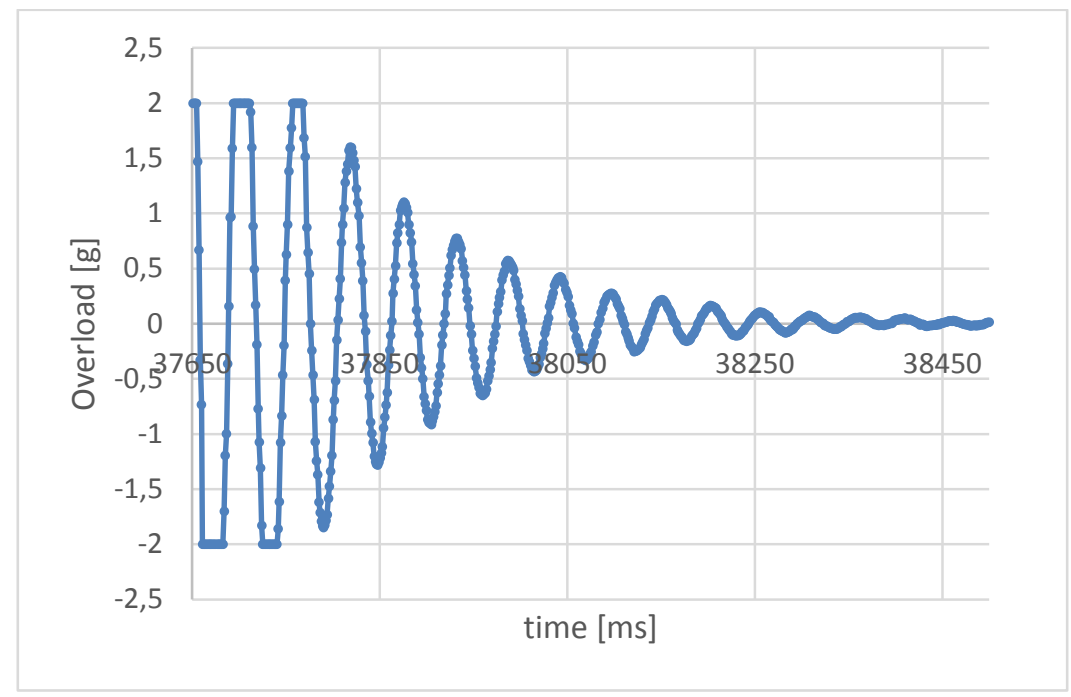

Fig. 12. Damped free vibration waveform in the time function

The next step in the research was to start the motor without a propeller. Data from each accelerator axis was sampled at a frequency of $1 \mathrm{kHz}$. The rotational speed was chosen, in case of which one angle value of the shaft position corresponded to one acceleration set $\boldsymbol{a}_{\boldsymbol{x}}$, $\boldsymbol{a}_{\boldsymbol{y}}, \boldsymbol{a}_{z}$. Knowing that the encoder performs 48 counts per complete shaft rotation, the number of rotations per time unit of $1250 \mathrm{rpm}$ was determined. For such selected settings, overloads from each accelerometer with an assigned angular position of the shaft were recorded. The measurement results are presented in fig. 13 and fig. 14. Analysing data from the upper 
sensor, it can be seen that the amplitude of vibrations resulting from the residual unbalance is within $\pm 0.05 \mathrm{~g}$. According to the authors, the course of diagrams for overloads within the axes $\boldsymbol{x}$ and $\boldsymbol{y}$ should have a course similar to harmonic one with a shift in the $90^{\circ}$ phase. Figure 13 shows overloads from the sensors in a function of the angular position of the shaft. The low amplitude indicates the correct motor balancing.

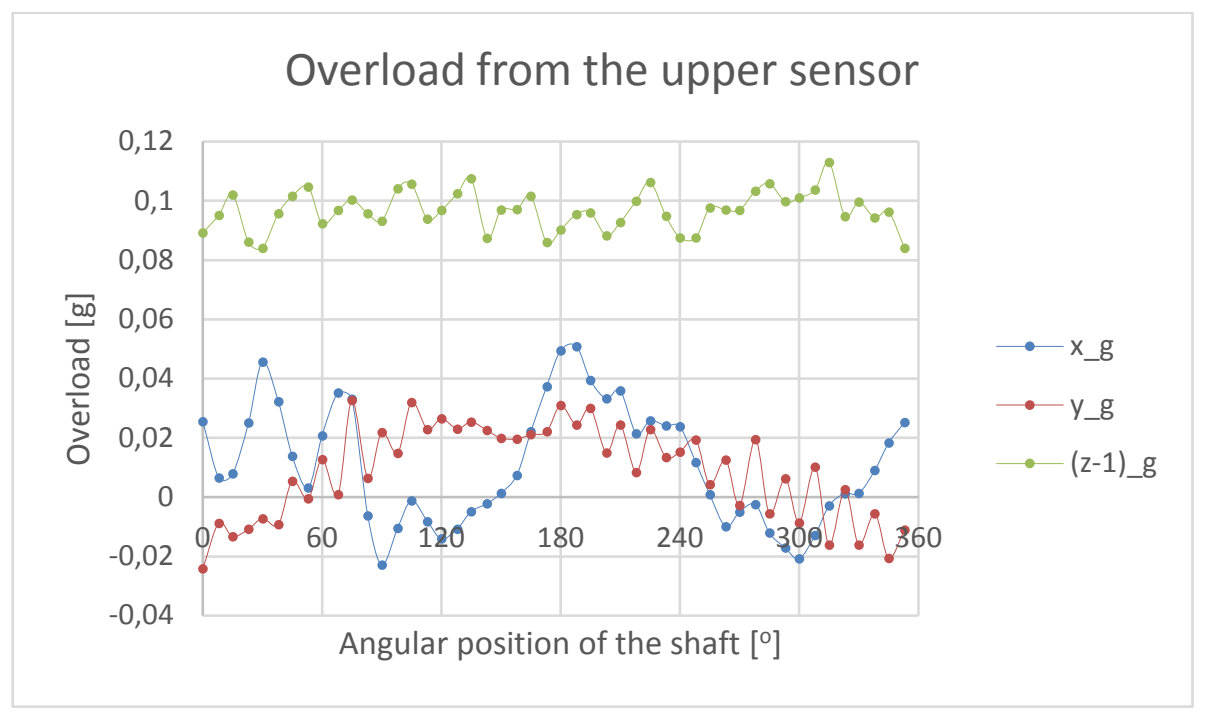

Fig. 13. Overload values from the upper accelerator for the balanced motor

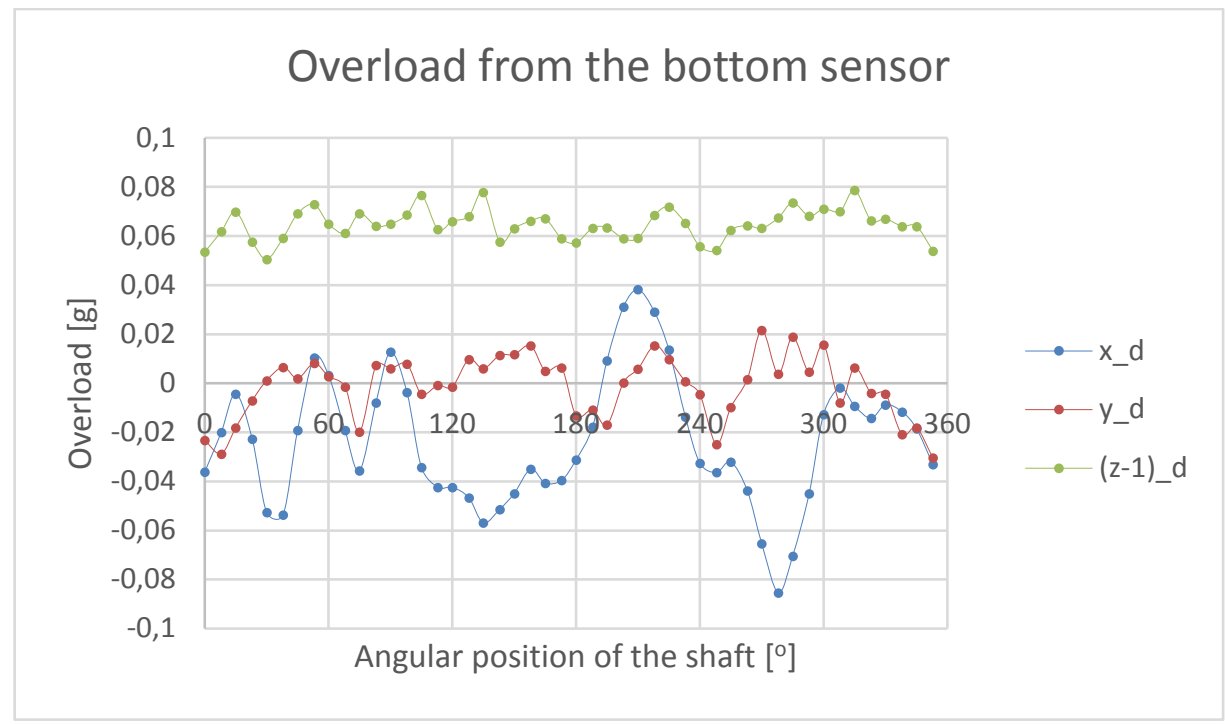

Fig. 14. Overload values from the bottom accelerator for the balanced motor 
At a later stage of works, a known mass $m_{1}=0,8 \mathrm{mg}$ on a known radius $r_{1}=7 \mathrm{~mm}$ was added to the motor housing, owing to which the motor was put into an unbalanced state. The overload values, which were presented in fig. 15 and fig. 16, were recorded. The analysis of fig. 15 shows that the courses of the overload values in the axes $\boldsymbol{x}$ and $\boldsymbol{y}$ are similar to a sinusoid. For the $150^{\circ}$ and $330^{\circ}$ shaft positions, the vibration amplitude reaches a maximum value of approximately $\pm 0.25 \mathrm{~g}$.

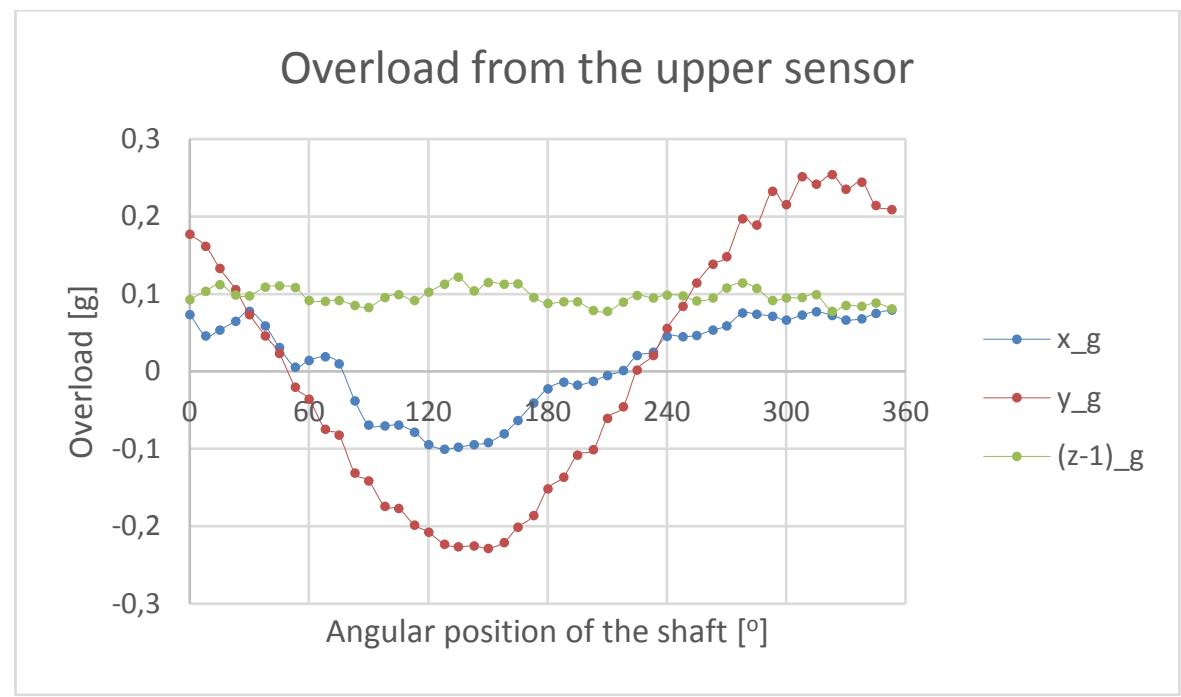

Fig. 15. Overload values from the upper accelerometer for the unbalanced motor

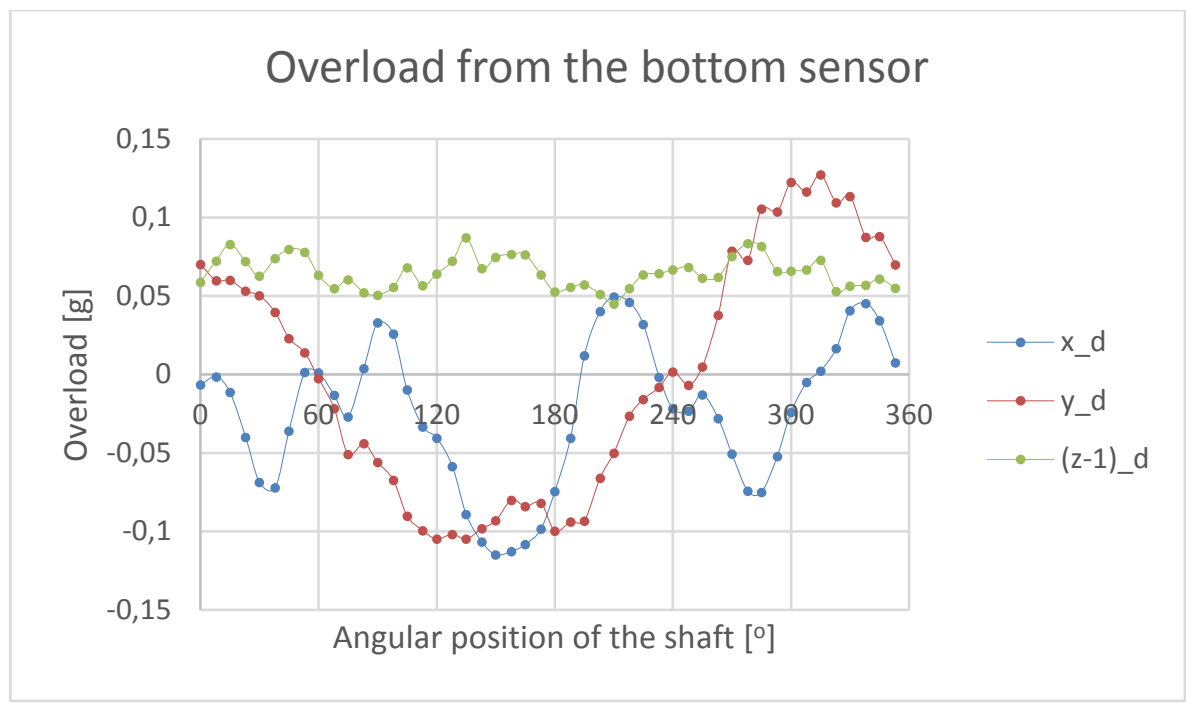

Fig. 16. Overload values from the bottom accelerometer for the unbalanced motor 
The last step was to add the mass $\mathrm{m}_{2}$ equal, in terms of value, to the mass $\mathrm{m}_{1}$ on a radius $r_{2}$ equal to $r_{1}$ in terms of value, but in the opposite direction, to the previously unbalanced rotor. The result of this operation was demonstrated in fig. 17 and fig. 18. Owing to this action, the vibration amplitude for the upper sensor in the axes $\boldsymbol{x}$ and $\boldsymbol{y}$ decreased again to the level of $\pm 0.04 \mathrm{~g}$, approximately to the initial value.

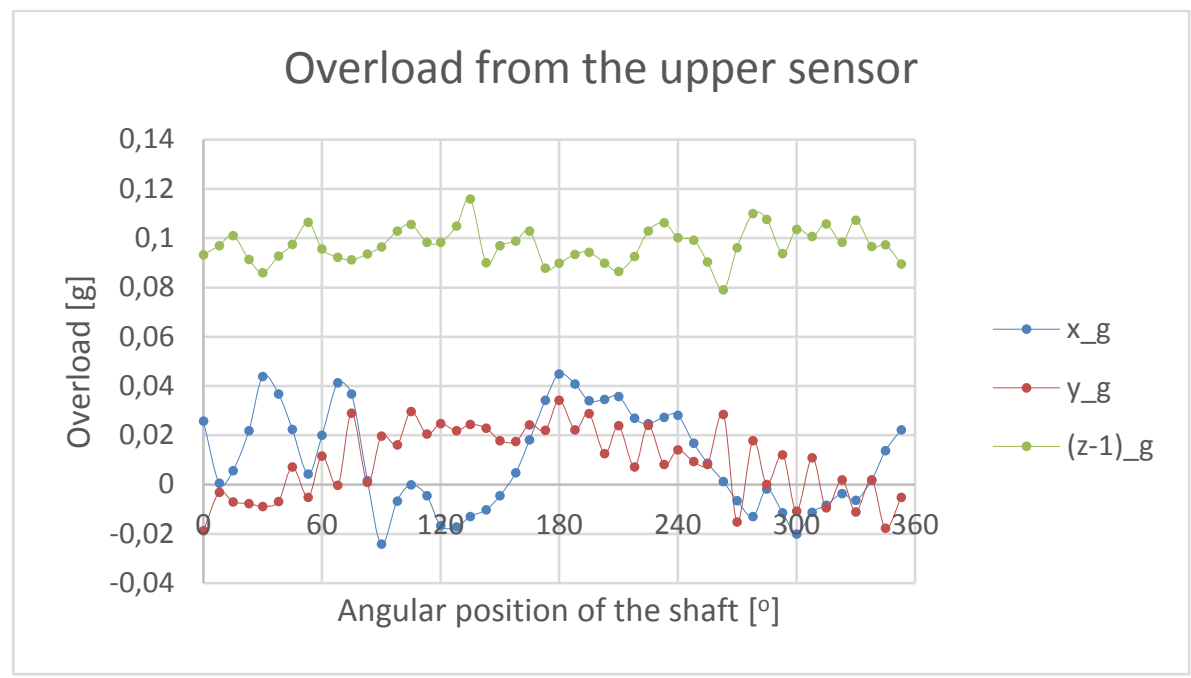

Fig. 17. Overload values from the upper accelerator for the balanced motor

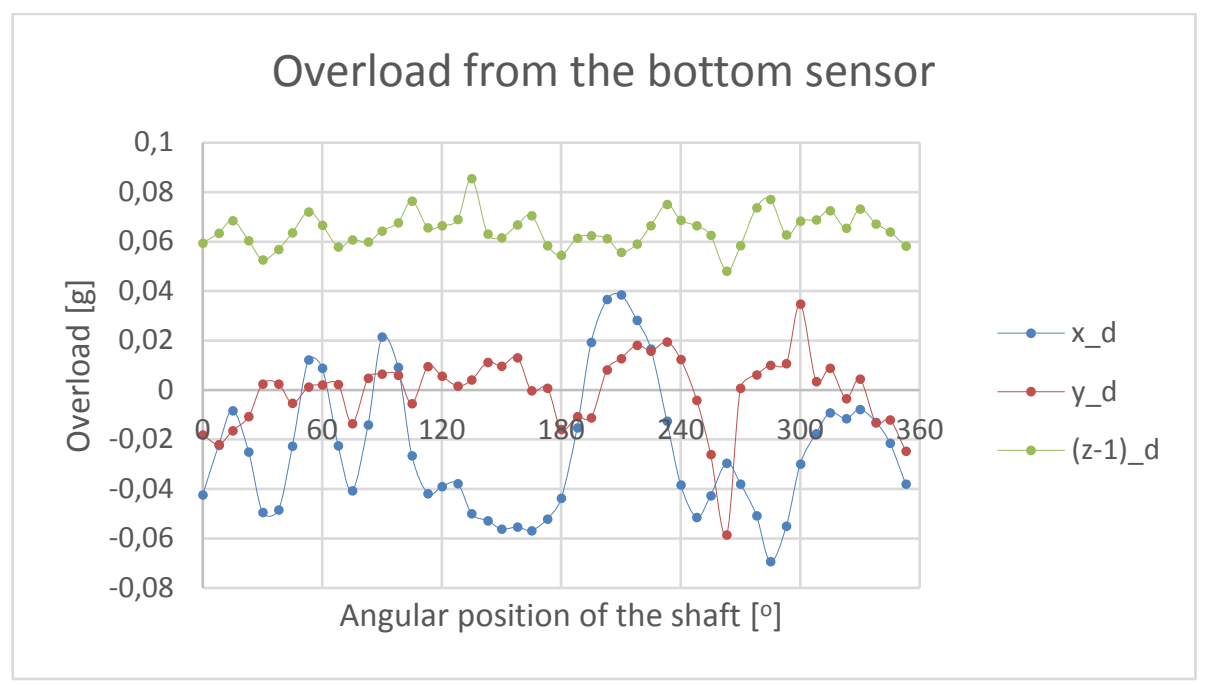

Fig. 18. Overload values from the bottom accelerator for the balanced motor 
For example, the diagrams in fig. 19 and fig. 20 were placed, where the overload courses were presented for the case, in which for the angle of setting the shaft of $90^{\circ}$ on the outer side of the rotor, the mass with the value of $1.05 \mathrm{~g}$ was glued. The rotational speed of $1250 \mathrm{rpm}$ was set. It can be seen from the analysis of the first diagram, fig. 18, that the range of angles from $80^{\circ}$ to $100^{\circ}$, the vibration amplitude reaches its maximum. Owing to this method, it becomes possible to determine the place of unbalance. The value of the balancing mass, at this stage, is implemented by the comparative method, i.e. after adding the known mass in a specific place, it is possible to observe the vibration amplitude. If the amplitude is still high, then it is important to increase the mass and observe the results.

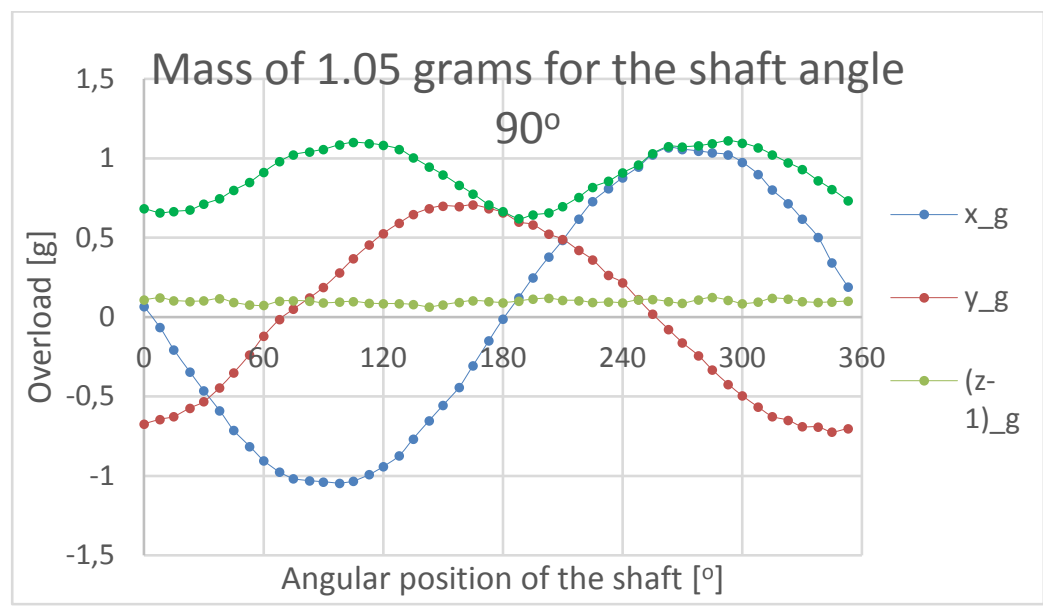

Fig. 19. The course of overloads for the known mass and shaft angle from the upper accelerometer

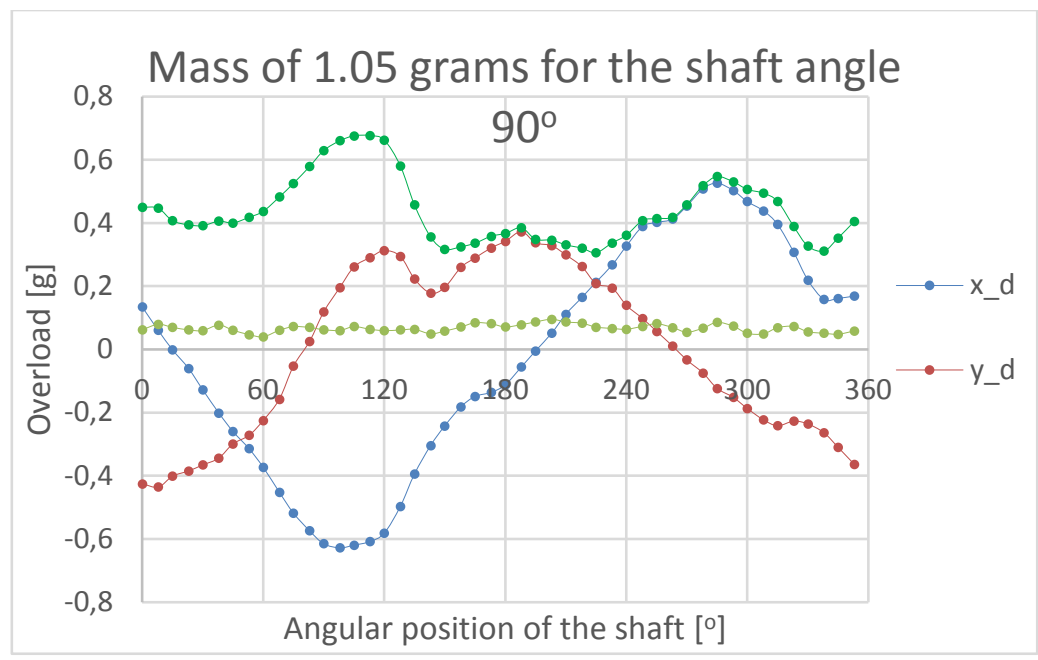

Fig. 20. The course of overloads for the known mass and shaft angle from the bottom accelerometer 
The research implemented an attempt to balance the entire power unit with the 13 ", propeller, which was set a rotational speed of $1040 \mathrm{rpm}$ - close to the natural vibration frequency. Figure 21 presents the overload courses in the angular shaft position function before balancing, while fig. 22 presents the courses after balancing. On the basis of the analysis of amplitudes of both diagrams, it can be concluded that adding the mass of $2.3 \mathrm{~g}$ on the motor circuit for the angle of $160^{\circ}$ calculated from the axis $\mathrm{x}$, affects an over 10-time decrease in the vibration amplitude level of the power unit. In addition, putting the power unit into the state close to the resonance allows to increase the amplitude.

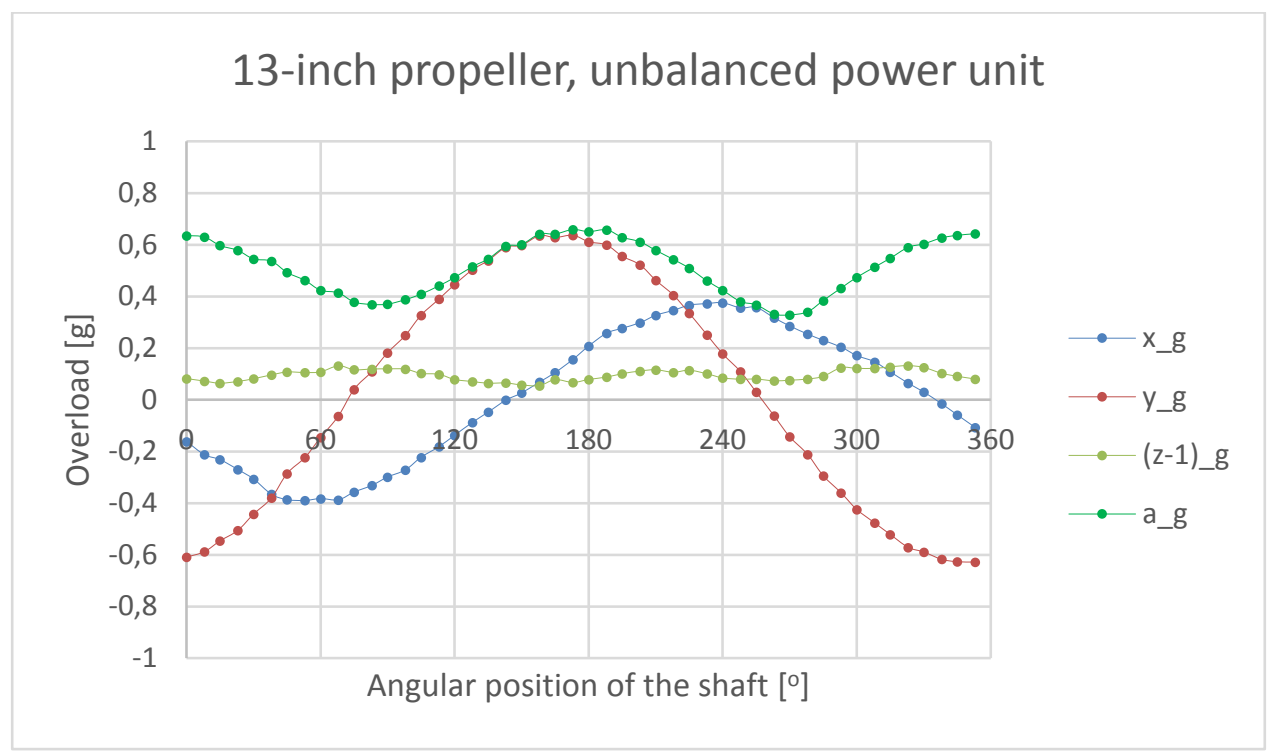

Fig. 21. Power unit before balancing 


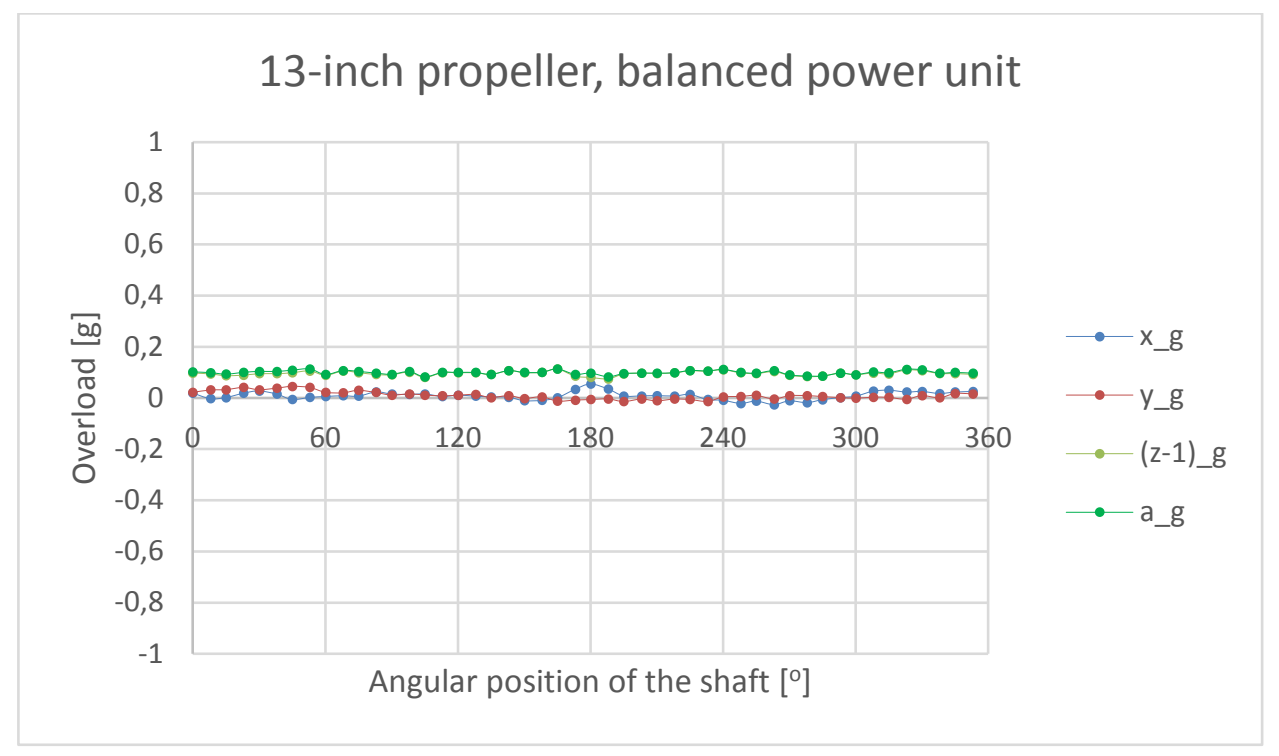

Fig. 22. Balanced power unit

\section{Conclusion}

Within the framework of the studies, a laboratory stand was performed, and preliminary balancing tests of the motor and power unit were conducted. It was found that the accuracy of measurements affects the connection of the angular position of the shaft and instantaneous acceleration values. The measurements were made for two rotational speeds expressed in rpm. One of the speeds was similar to the resonance frequency, and the other for identical sampling frequencies of the encoder and accelerometers. The conclusion resulting from the studies is the fact that an increase in the overload amplitudes was observed at approximately resonance speed, making it easier to link the maximum vibration amplitude with the angular position of the shaft.

At the next stage of work, it is planned to develop algorithms that facilitate calculation of the balancing mass values.

\section{Acknowledgement}

The work was carried out within the framework of Statutory Research conducted at the Air Force Institute of Technology in Warsaw. 


\section{References}

1. Brada M., Štorch V., Nožiča J.: Experimental setup for measurement of contra-rotating propellers. Topical Problems of Fluid Mechanics, Prague 2017.

2. Cioch W.: Rodzaje i sposoby korekcji rozkładu masy wirników maszyn obrotowych. Materiały dydaktyczne, Akademia Górniczo-Hutnicza im. Stanisława Staszica w Krakowie, [access:2019-12-18]. Available in Internet: http://home.agh.edu.pl/ $\sim$ cioch/WYW_T.PDF

3. Delgado-Arredondo P.A., Morinigo-Sotelo D., Osorino-Rios R.A., et al.: Methodology for fault detection in induction motors via sound and vibration signals. Mechanical Systems and Signal Processing, vol. 83, 2017.

4. Goliński J.A.: Wibroizolacja maszyn i urządzeń. Wydawnictwa Naukowo-Techniczne, Warsaw 1979.

5. Leyko J.: Mechanika ogólna. Państwowe Wydawnictwo Naukowe, tom II, Warsaw 1969.

6. Mizui M., Yamamoto I., Ohsawa R.: Effects of Propeller-balance on Sensors in Smallscale Unmanned Aerial Vehicle. IOSR Journal of Engineering, vol. 2, iss. 8, 2012.

7. Zhou S., Shi J.: Active Balancing and Vibration Control of Rotating Machinery: a Survey. University of Michigan, The Shock and Vibration Digest, vol. 33, no. 5, 2001. 